\title{
USO DO PRONOME SUJEITO DE PRIMEIRA PESSOA NO PORTUGUÊS DO BRASIL
}

\author{
Odete Pereira da Silva Menon
}

RESUMO: Le portugais est encore considéré une langue à sujet nul. Néanmoins, des recherches sur l'emploi $d u$ pronom sujet auprès $d u$ verbe présentent des résultats qui vont dans le sens contraire, indiquant plutôt un changement en cours dans le portugais du Brésil. Pour vérifier si la morphologie verbale est encore pertinente pour l'absence des pronoms, surtout ceux de première personne, on a choisi un échantillon composé des interviews du Projet NURC de São Paulo, du type le plus formel, les EFs. - Ellocutions Formelles, constituées de cours et conférences. Les données, classées par des facteurs aussi structuraux que sociaux, ont été soumises au logiciel VARBRUL.

PALAVRAS-CHAVE: Sujeito nulo, pronomes de primeira pessoa, Projeto NURC/SP, português do Brasil, variação e mudança.

\section{INTRODUÇÃO}

Vários trabalhos têm debatido a questão de o português ser, ou não, uma língua de sujeito nulo, ou seja, cuja morfologia verbal seria suficientemente "rica" para dispensar o uso do pronome sujeito junto ao verbo (cf., entre outros, DUARTE, 1993, 1995; GALVES, 1993; KATO, 1976; LIRA, 1988; MONTEIRO, 1994; NARO \& LEMLE, 1977; NICOLAU, 1994; OLIVEIRA, 1986; ROBERTS, 1993; TARALLO, 1985).

No entanto, a questão posta desta maneira escamoteia dois aspectos: primeiro, o fato de uma língua ter morfologia verbal "rica", com formas marcadas para todas, ou quase todas as pessoas, não constitui empecilho para uso obrigatório do pronome, como é o caso do alemão ou do holandês. Segundo, afirmar que o português está em vias de modificar seu estatuto e que anteriormente não havia o uso do pronome baseia-se em fontes escritas e não em fontes orais. Ora, sabemos todos como funciona a auto-censura no ato de escrever e, no caso de publicações, como os revisores, muitas vezes, se dão o "direito" de cortar os pronomes que eles acham demasiados. Também deve se levar em conta que os professores em geral

Odete Pereira da Silva Menon - Universidade Federal do Paraná. 
riscam os pronomes dos textos (redações) escolares dos alunos, descontando nota por causa desses "erros" ${ }^{1}$.

Nos estudos já realizados sobre o assunto, a distribuição dos dados tem demonstrado que há diferentes resultados entre uso e não-uso do pronome segundo provenham de língua oral ou da língua escrita. Paredes da Silva (1988), ao analisar um córpus de cartas pessoais, demonstrou que o percentual de uso do pronome na escrita é mais baixo que o constatado em trabalhos que têm a língua oral como fonte. Duarte (1993, p.121-122), quando compara resultados sobre o desempenho dos atores, mostrou diferenças na realização oral em relação ao texto escrito: na encenação de peças, eles realizaram mais pronomes do que existiam no roteiro (escrito e decorado)...

Enfim, há uma consideração importante de Benincà (1993, p.256-257), a respeito do italiano, que sempre é mencionado como língua prototipicamente pro$d r o p^{2}$, ao lado do espanhol. Diz a autora que considerar o italiano como língua pro-drop depende de que tipo de relacionamento entre ele e os outros dialetos românicos na Itália se leva em consideração:

Consideriamo una tipologia ben studiata e descritta dalla teoria sintattica di questi ultimi decenni, quella che riguarda la 'forza pronominale' del verbo flesso. Una lingua a soggetto nullo è una lingua in cui il verbo flesso può da solo essere sufficiente a esprimere anche il soggetto pronominale: così era il latino, così è l'italiano o lo spagnolo. Forme verbali come camminiamo, arriverete, andrò sono perfettamente autonome e costituiscono delle frasi complete: sono necessarie solo conoscenze specifiche del contesto della situazione per interpretarle correttamente. Lingue come il francese, o l'inglese, o alcuni dialetti settentrionali italiani, devono aggiungere un elemento pronominale; se manca un soggetto referenziale, il verbo flesso non è sufficiente. Si dice che queste lingue sono a soggetto obbligatorio. L'italiano scritto, fino quando a mantenuto $i$

\footnotetext{
${ }^{1}$ Para ilustrar como se repercute nos alunos a questão da fobia pelo uso dos pronomes sujeito, sobretudo o de primeira pessoa: em 1994, no vestibular da UFPR, a prova de redação consistiu em fazer um texto respondendo à questão: Você adotaria uma criança? A resposta exigia o uso do pronome pessoal eu, visto que era uma pergunta dirigida diretamente ao interlocutor. Ora, o que se viu foi um conjunto de manobras lingüísticas para evitar o uso desse pronome, como resultado de uma política, sobretudo dos cursinhos preparatórios, que imputava na cabeça do pobre vestibulando que, se ele ousasse empregar $e u$, seria por isso penalizado. As estratégias de que lançaram mão os candidatos foram surpreendentes, em alguns casos: todo o tipo de indeterminação/ generalização/ indefinição foi empregado: a gente/ nós/ a pessoa/ todos/todo mundo/ todo ser humano/ todas as pessoas/ a sociedade em geral/ os adultos/ os casais/ as pessoas de posse/ uma/ qualquer pessoa com condições financeiras ... Mas o caso mais surpreendente, e que revela bem o estado de coisas a que a escola submete os alunos, foi a de um candidato que começou sua redação da seguinte maneira: a primeira pessoa deveria adotar uma criança... Ao usar um recurso metalingüístico, o candidato não só evitou o uso do pronome, como denunciou o labirinto de estratégias a superar a fim de se safar de uma impugnação da prova, por uso de recurso "condenável". Todos os que participaram dessa correção puderam avaliar a angústia dos candidatos em decidir se respondiam à questão, como era esperado, e se expunham a uma anulação, ou se não respondiam à questão, o que levaria a resultado semelhante: punição, de alguma forma, em ambos os casos.

${ }^{2} \mathrm{Na}$ terminologia gerativista, esse seria o nome do parâmetro que teriam as línguas que licenciam o sujeito, ou seja, prescindem do uso do pronome sujeito.
} 
contatti con la varietà de Firenze, può essere visto sia come una lingua a soggetto nullo com forti tendenze a diventare una lingua a soggetto obbligatorio, sia, all' opposto, come una lingua a soggetto obbligatorio con elementi che mostrano una evoluzione in atto verso una lingua a soggetto nullo $^{3}$ : così è tuttora il dialetto di Firenzi, così era ancora all' inizio del secolo il dialetto di Pisa, ultime propaggini verso sud del tipo sintattico proprio delle varietà romanze dell' Italia settentrionale.

Assim, segundo Benincà, essa afirmação sobre o italiano teria que ser modalizada ou reavaliada. Não sabemos se esse seria o caso do português. Para isso, dependeríamos de ter descrições de outros dialetos, do território lusitano, o que ainda não existe. Também não dispomos de estudos diacrônicos em quantidade suficiente sobre as realizações na escrita, em diferentes épocas. Só tendo à mão resultados demonstrando diferenças, ou não, de uso do pronome é que poderíamos tecer considerações razoáveis a respeito.

Quanto à questão dos contextos, há diferentes realizações: Soares (1994), se apoiando no trabalho de Paredes da Silva (1988), mostra que não é só (i) o ambiente lingüístico em que se encontra o verbo ou (ii) considerações concernentes a tipos de oração, ou (iii) se a oração anterior tem ou não sujeito preenchido, ou (iv) se o sujeito da oração anterior ou posterior é igual ou diferente, ou, ainda, (v) qual é a distância entre o sujeito e o verbo, é que determinariam ou poderiam condicionar a ocorrência do pronome sujeito. Considerações de tipo semânticodiscursivo também teriam que ser levadas em conta: informação nova versus informação velha, graus de conexão do discurso...

\section{MORFOLOGIA RICA?}

Pelo menos no tocante à variedade padrão, tal qual é ensinada nas escolas, existiria no português uma distinção morfológica suficiente para dispensar o uso do pronome junto ao verbo, com marcas distintivas para todas as pessoas em muitos dos tempos e com alguma coincidência em outros, o que não constituiria problema.

Ora, de um lado, a norma escolar continua apresentando um paradigma verbal contendo tu e vós (bem marcados, sempre) para as segunda e quinta pessoas, quando sabemos que, pelo menos no $\mathrm{PB}$ (português do Brasil), vós não faz parte de nenhum dialeto oral, salvo em contextos bem específicos, como o uso na liturgia católica ${ }^{4}$. Seria provável, também, que se apresentasse um contraargumento, o de que na produção literária em versos, mesmo em autores jovens, continuaria a ser produtivo o emprego do pronome $t u$. Porém, consideramos que, neste caso, assim como em algumas manifestações musicais, trata-se de forma cristalizada, ligada intimamente ao estilo empregado em poesia. Um autor

\footnotetext{
${ }^{3}$ Grifo meu.

${ }^{4}$ A liturgia das igrejas reformadas usa $t u$, mesmo quando o dialeto regional não tem esse pronome de 2 . pessoa. Mas, em ambos os casos, é bom lembrar que os fiéis lêem/recitam textos (Bíblia; textos referentes ao culto/missa); não se trata, pois, de uma real produção de língua por parte deles.
} 
paranaense, Paulo Leminski, escreveu poesias e letras de músicas usando o $t u$, pronome que não empregava normalmente. $\mathrm{O}$ uso de $t u$, em poesia, produziria imediatamente "efeito lírico".

Por outro lado, aquela norma ignora a existência de você(s) para a 2 ." pessoa (respectivamente, do singular e do plural) e de a gente para a 1. pessoa do plural, "novos" pronomes pessoais da língua portuguesa, introduzidos no paradigma por gramaticalização (MENON, 1994b, 1995b,c, 1996, 1998; BRAGA \& OMENA, 1996) de locuções nominais (doravante LNs. ${ }^{5}$ ). Na mesma situação se encontra $o(a)$ senhor $(a)$, embora esses três pronomes apareçam nos textos dos livros e nos exercícios.

A atitude dos autores de manuais escolares e livros didáticos é de acordo tácito: os "novos pronomes" aparecem nos textos, nos exercícios, mas não se fala neles; como todo mundo sabe como funcionam, já que todos usam, não é preciso se incomodar com eles... Aliás, esses autores não sabem como lidar com muitos fatos da língua: você(s) aparece numa seção intitulada ora como formas de tratamento ora como pronomes de tratamento, onde também aparece, às vezes, o(a) senhor(a). No entanto, na Morfologia, quando se trata da classe dos pronomes, não aparece na lista esse tipo de pronome: ele aparece como um apêndice, sem outra explicação. Com relação a a gente, a situação é pior: os autores continuam a enfocar esse pronome como sendo o substantivo feminino gente. Por isso, a gente, em geral, só aparece nos apêndices relativos a figuras de construção / figuras de sintaxe, sob o rótulo de silepse de concordância, seja nominal, correspondente a "desvios" ou a concordância psicológica ou ideológica, seja verbal, por idênticos motivos, ou, ainda, como silepse de gênero, quando não acontece a concordância nominal de predicativos ${ }^{6}$. A gente só é realmente tratado como um pronome por Cuesta \& Luz (1980, p.402); por Said Ali (1971, p.116), que faz alusão ao caráter pronominal de a gente (e de homem) quando é utilizado "não já na acepção própria, mas para indicar um agente vago e indeterminado."

Enquanto a norma escolar continua a pregar esse paradigma, ignora que a introdução dos três pronomes na língua portuguesa, apesar de ter sido em diferentes momentos e com comportamento diverso nos dialetos, teve como conseqüência o desaparecimento daquelas marcas morfológicas, visto que os referidos pronomes têm em comum o fato de se originarem de LNs. cristalizadas. Na origem, a concordância verbal com as LNs é feita na 3. ${ }^{a}$ pessoa pois, não sendo nem primeira, nem segunda, os nomes (lembremos que a LN equivale a um nome)

\footnotetext{
${ }^{5}$ Locuções nominais são denominadas por alguns autores como SNs - Sintagmas Nominais.

${ }^{6}$ Conforme os seguintes exemplos, citados em Menon (1994, p.195-196): Povoavam os degraus muita sorte de gente (M.B.)(Pereira, 1948, p.251); A gente está disposto.(Guérios, 1964, p.280); A gente já está atrasado e você continua a falar. (Oliveira, s/d, p.355); Quando a gente é novo, gosta de fazer bonito. (G.Rosa); A gente, quando vai ensurdecendo, também vai ficando isolado. (G.R.); A gente é obrigado a varrer até cair morto. (Josué Guimarães) (Cegalla, 1980, p.404); Nas camadas inferiores, os coletivos gente, pessoal tomam o verbo no plural: A gente vamos hoje. O pessoal foram convidado. (Nascentes, 1953, p. 170). 
só podem reger a $3{ }^{a}$ pessoa. Como na língua os fatos não acontecem isoladamente, a mudança do estatuto gramatical das LNs (o processo de gramaticalização) não acontece como mudança única: os falantes não variam e mudam só as locuções; pelo contrário, é porque as locuções mudam sem mudar muito, conservando a forma verbal e os outros pronomes do sistema, que as variações, tanto fonéticas quanto de situação pragmática - quem usa o quê; com quem; quando e em que contexto - acabam por se impor na língua comum (ou até na escrita). Na língua oral o continuum não é só de produção mas de encadeamento, e as (auto- ou hetero-) correções, quando acontecem, são novos enunciados que não alteram o que já foi dito e, portanto, registrado pelo receptor (que já decodificou a mensagem e simplesmente registra a correção). Além disso, como o material fônico que se interpõe entre o pronome sujeito e o verbo normalmente não é longo (como pode acontecer na escrita), se automatizou a realização diferenciada da locução, sem se alterar a forma verbal.

Em decorrência desse processo, se introduziu no paradigma verbal uma forma não-marcada morfologicamente, que é igual à da $3{ }^{\mathrm{a}}$, e à da $6 .^{\mathrm{a}}$ no caso de vocês, o que reduziu o número de contrastes morfológicos ${ }^{7}$, uma vez que tanto $a 2 .^{a}$ $\left(\right.$ tu ${ }^{8} /$ vocêlo senhor), quanto a $3 .^{a}$ (ele) e $4 .^{a}$ (a gente) pessoas passam a ter o mesmo morfema número-pessoal e, em alguns tempos verbais, como os imperfeitos (do indicativo e do subjuntivo), os futuros (do indicativo e do subjuntivo) ou o condicional, ele coincide com o de $1 .{ }^{a}(e u)$ pessoa. Da mesma forma, a 5. ${ }^{\mathrm{a}}$ (vocês) $\mathrm{e}$ a $6 .{ }^{\text {a }}$ (eles) pessoas passam a ter identidade morfológica.

De acordo com Roberts (1993), semelhante fato ocorreu também no francês antigo, o que redundou na perda, para o francês moderno, do parâmetro pro-drop, uma vez que existe um limite na capacidade de uma língua de tolerar semelhanças e coincidências. Diz ele ( e Duarte (1993) retoma essa perspectiva para o português) que a redução das oposições paradigmáticas do francês chegou ao seu limiar de possibilidades quando houve (na língua oral) uma identidade entre as três primeiras pessoas e, em alguns casos, com a última. A língua escrita ainda conserva um paradigma marcado para as cinco e, às vezes, para as seis pessoas ${ }^{9}$, mas a realidade oral já não registra mais todas essas diferenças. Além disso, em

\footnotetext{
${ }^{7}$ Outros fenômenos, como a desnasalização, teriam contribuído para uma identidade de formas entre a 3. ${ }^{\text {a }}$ pessoa do singular e a do plural (e entre a segunda e a terceira do plural) de certos verbos. Nesse caso, poderia chegar a uma identidade total de ausência de marca morfológica no verbo, num tempo como o imperfeito do indicativo: eu fazia, tu/(v(o)cê fazia, ele fazia, a gente fazia, (v(o)cês fazia, (el)es fazia. Os parênteses em você/ vocês; eles indicam supressão de sons em pronúncias atestáveis em alguns dialetos e/ou registros: ocê/ cê; es.

${ }^{8}$ Em relação à concordância verbal com o pronome $t u$, ver Menon (1995b) e Loregian (1996).

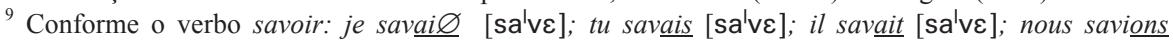
[savi'õ], vous saviez [savi'e], ils savaient [sa've]:as primeira, segunda e terceira pessoas do singular mais a terceira do plural têm exatamente a mesma pronúncia. Se o falante utilizar on para a primeira pessoa do plural, acrescenta-se a quinta ambigüidade: on savait [sa've].
} 
francês moderno, com o uso de on concorrendo com nous, acrescenta-se mais uma identidade morfológica, semelhante ao que acontece no português com a gente ${ }^{10}$.

Essa é uma perspectiva que diz respeito ao desaparecimento de marcas como a primeira das razões para um uso mais freqüente do pronome sujeito no $\mathrm{PB}$, que seria maior à proporção que crescesse a identidade de formas verbais. Tal identidade exigiria, sobretudo na retomada anafórica em contextos onde mais de um pronome está presente, um uso quase obrigatório do pronome sujeito. A repetição do emprego do pronome sujeito pelo falante, em semelhantes casos, poderia criar um certo automatismo na produção, juntando o pronome ao verbo e, na transmissão, a geração seguinte poderia interpretar o fato como obrigatoriedade. $\mathrm{Na}$ seqüência, a extensão do uso do pronome, para contextos que não apresentam ambigüidade, poderia constituir a segunda etapa do processo que levaria à obrigatoriedade do uso do pronome sujeito e à conseqüente perda do parâmetro pro-drop. Desse ponto de vista, o português estaria se encaixando perfeitamente no modelo.

\section{MORFOLOGIA POBRE?}

Parece haver, no entanto, outros condicionamentos que regulam o uso do pronome. A existência de línguas com morfologia rica que exige o uso do pronome sujeito mostra que, de alguma forma, o peso da marca verbal não constitui empecilho para a língua não ser pro-drop.

Além disso, acreditamos que as afirmações por parte de gramáticos de que o português dispensa o pronome decorre do modelo de descrição gramatical latino: já que o latim prescindia do uso dos pronomes, o português também poderia (deveria) fazê-lo. Cabe discutir o fato de que, já na constituição histórica das línguas românicas, houve divergências em relação ao latim. No tocante aos pronomes pessoais sujeito, a criação do pronome de $3 .^{\text {a }}$ pessoa, oriundo do demonstrativo ille, illa, illud, já evidencia uma necessidade de essas línguas marcarem a pessoa verbal por meio de pronomes. É bom lembrar que em latim só existiam pronomes de 1 a $^{\mathrm{a}} \mathrm{e} 2{ }^{\mathrm{a}}$ pessoas - ego, $t u$, nos, vos -, e que esses só eram empregados em contraste ou em vocativo. Para indicar a chamada $3 .^{a}$ pessoa, existia uma série de pronomes que, normalmente, são classificados como demonstrativos $^{11}$. Uma criação de tal amplitude nas línguas românicas não teria ocorrido se não fosse importante e necessário evidenciar o sujeito. Assim, pode se questionar uma afirmação que se tornou banal nos estudos sobre o sujeito nulo e também se colocar o fato de alguns autores questionarem, para o latim, sobretudo o falado, a não-ocorrência de pronomes junto ao verbo. Para essa língua, assim como

\footnotetext{
${ }^{10}$ A respeito da gramaticalização de a gente, ver Menon (1994b, 1995b,c, 1998). Em Menon (1995a) há considerações sobre o uso de a gente com a forma marcada -mos, conforme também Omena (1986, apud Menon (1995a)) para o dialeto carioca.

${ }^{11}$ Conforme Magne (1929, p.99): " $A$ terceira pessoa não tem pronome não reflexivo; elle traduz-se com o pronome ille ou outro demonstrativo."

162
} 
para fases anteriores do português, permanece o fato de que os dados disponíveis são todos de textos escritos. Somente cartas pessoais se aproximariam, de alguma forma, das variedades orais, assim como algumas peças de teatro ${ }^{12}$, sobretudo de autores "malditos". Vimos anteriormente como Duarte (1993) demonstrou que, na comparação entre interpretação e roteiro, os atores usam mais pronomes em cena.

Toda a questão parece girar em torno do significado: como a morfologia verbal já conteria a noção de pessoa do discurso, o pronome junto ao verbo seria redundante pois nada acrescentaria em termos de informação nova. Parece que esse princípio é aceito sem nenhuma ressalva. No entanto, achamos que se deve fazer ao menos duas perguntas:

a) será que o morfema verbal número-pessoal contém realmente a informação relativa à pessoa do discurso ou esta noção é decorrente da informação metalingüística que aprendemos na escola? Não conhecemos nenhum estudo sobre atitude dos falantes (não-alfabetizados) a respeito. Pontes $(1986,1987)$ evidenciou como a identificação do sujeito, mesmo por pessoas altamente escolarizadas, é difícil. Essa difículdade não residiria na (in)capacidade (resultante, talvez, de um esvaziamento de sentido) de a morfologia conter o significado ${ }^{13}$ de pessoa verbal? Monteiro (1994, p.135), ao comentar os resultados obtidos no uso de todos os pronomes (em que os pesos relativos foram sempre acima do ponto neutro, exceto para ele(s)), ressalta:

Queremos insistir no fato de que a terminação verbal parece exercer menos influência do que a noção semântica de pessoa do discurso. Se não, os pronomes ele, você e a gente de um lado, bem como eles e vocês de outro, teriam probabilidades idênticas. [...] Diante disso, é imperioso admitir que uma rede complexa de fatores controla o emprego ou omissão dos pronomes sujeitos.

b) será que o pronome sujeito contém fortemente o significado de pessoa do discurso, como costuma se apregoar ou, ao contrário, o falante não se daria conta de que o está empregando, porque ele se esvaziou de sentido? Lembremo-nos de como se processa o ensino de conjugação verbal na escola: todos aprendemos a "conjugar" o verbo junto com o pronome, tal qual uma ladainha, em que não nos damos conta do que dizemos, em função do ritmo e da entonação. O aluno, por decoreba, aprende a recitar eu canto, tu cantas, ele canta, nós cantamos, vós cantais, eles cantam. Adquire, pois, um hábito que reforça, provavelmente, o que ele já produz

\footnotetext{
${ }^{12}$ Para o latim, costuma-se servir das cartas pessoais de Cícero, por exemplo, ou das peças de Plauto, para fazer referências a traços das variedades orais.

${ }^{13}$ No entanto, poderíamos também nos questionar por que as pessoas menos escolarizadas produzem o verbo com o morfema -mos ao lado do pronome $a$ gente. Seria por hipercorreção, conforme Menon (1995a)? Perini (comunicação pessoal) diz acreditar que, de alguma forma, a concordância é semântica.
} 
em seu dialeto. Depois, a escola quer reparar o "erro", quando o professor tinge de vermelho as redações, ao cortar pronomes, a seu ver desnecessários, produzidos automaticamente pelo aluno.

Diante dessas duas colocações, vamos mostrar os resultados obtidos em Menon (1996), em que nos propusemos a testar qual seria ainda o peso da morfologia verbal. Para isso, escolhemos trabalhar com dados do projeto $\mathrm{NURC} / \mathrm{SP}^{14}$, mais especificamente as gravações do tipo $\mathrm{EF}^{15}$ - Elocuções Formais - , por ser esse o tipo de registro mais formal de língua, uma vez que se trata de registro de aulas e conferências. Além disso, os informantes do NURC são de escolaridade universitária o que, na época em que foram realizadas as entrevistas, era o grau mais elevado ${ }^{16}$ de educação formal a aspirar pela população em geral (na realidade, pela elite, pois o sistema universitário da época não contava ainda com a proliferação dos cursos noturnos).

Centramos nosso objeto nas ocorrências de $1 .^{\text {a }}$ pessoa do singular, marcada morfologicamente na maioria dos tempos verbais, e de 1. ${ }^{a}$ pessoa do plural (ou 4. ${ }^{\mathrm{a}}$ pessoa), por ser sempre marcada. Com essas características morfológicas bem definidas, consideramos que aí se evidenciaria aumento ou não do uso do pronome em função da faixa etária - ou análise em tempo aparente (LABOV, 1972) —, o que poderia caracterizar indícios de mudança em curso. Também, acessoriamente, poderia ser testada a influência da norma escolar sobre os indivíduos, na questão do uso do pronome junto ao verbo. Sempre se pressupõe que, quanto maior o nível de escolaridade, maior terá sido a influência da variedade padrão (cf. LABOV, 1972) sobre o dialeto do falante. No caso do NURC, como todos os informantes são de nível universitário, eles teriam, no mínimo, quinze anos de contato com a variedade padrão (presume-se que esse tempo corresponda ao contato passivo, ou seja, recepção; não se discute aqui o quanto eles teriam tido de produção).

\section{RESULTADOS}

Fizemos o levantamento das entrevistas, colhendo 1560 ocorrências de $1 .^{\mathrm{a}}$ pessoa. Submetendo os dados codificados ao pacote estatístico VARBRUL,

\footnotetext{
${ }^{14}$ O Projeto NURC (Norma Urbana Culta) se desenvolveu no período de 1971 a 1978 (variando conforme as cidades) em cinco capitais brasileiras: São Paulo, Rio de Janeiro, Recife, Porto Alegre (com mais de um milhão de habitantes em 1969) e Salvador (que, com 800 mil habitantes em 1969, foi escolhida ao invés de Belo Horizonte, capital com mais de um milhão de habitantes mas que não atendia ao critério de faixa etária, pois não tinha ainda quatro gerações nascidas na cidade). Esses e outros detalhes do NURC podem ser consultados em Menon (1994b).

${ }^{15}$ No NURC, além das EFs, há as entrevistas DID - Diálogo entre Informante e Documentador - e as D2 - Diálogo entre Dois Informantes, num decrescendo no nível da formalidade.

${ }^{16}$ Os cursos de mestrado e doutorado começavam então a se implantar no Brasil. Não se tendo um levantamento estatístico do registro de escolaridade de todos os informantes do projeto, não dá para se avaliar o percentual de informantes com curso de pós-graduação.
} 
fizemos rodadas conjuntas, para ver, primeiro, a distribuição dos dados (programa MVARB $)^{17}$, e em rodadas separadas, considerando a variável dependente o uso contra o não-uso de pronome junto ao verbo (programa IVARB). Do total de dados 938 são de $1 .^{\text {a }}$ pessoa do singular (629 com pronome e $309 \mathrm{sem}$ ) e $622 \mathrm{de} 1 .{ }^{\text {a }}$ pessoa do plural nós (377 com pronome e $245 \mathrm{sem}$ ). Lembramos que, como o objetivo do trabalho era estudar o papel da morfologia no uso do pronome, não foram consideradas as ocorrências de a gente, quando realizasse a 1 . $^{\mathrm{a}}$ pessoa do plural $^{18}$, por não ter morfema verbal próprio, conforme anteriormente discutido. Por isso, talvez pareça reduzido o número de ocorrências de $1{ }^{a}$ pessoa do plural se comparado com o do singular.

Consideramos como fatores sociais aqueles permitidos pelo próprio projeto NURC: sexo e faixa etária. Como fatores lingüísticos, pretendíamos testar: posição do pronome (antes/depois do verbo; não-aplicação); tipo de pronome (determinado, indeterminado, problema); marcas auxiliares (presença de pronomes possessivos ou objeto; elementos discursivos enfatizantes como próprio, mesmo, pelo menos, até, por exemplo); tipo de verbo (ligação, epistêmico, existencial, de estado, de ação, de percepção, dicendi, volitivo, modal); tempo verbal; tipo de ocorrência (para testar paralelismo); tipo de oração (absoluta, principal; coordenada: sindética, assindética, 1. ${ }^{a}$ de período coordenado, subordinada: substantiva, adjetiva, adverbial); conjunção (conjunção, pronome relativo, preposição); concordância com o infinitivo. Codificamos os dados segundo esses grupos de fatores, nove lingüísticos, dois sociais.

No entanto, após as rodadas iniciais do programa VARBRUL, ao chegarmos no arquivo de células, o MAKECELL, constatamos que não poderíamos usar esse arquivo como input ao MVARB ou ao VARB2000, pois havia grupos de fatores demais: 118, quando o máximo suportado pelo programa é de 100; além disso, foram detectados muitos nocautes ${ }^{19}$ (muitos eram esperados, tendo em vista a pulverização de possibilidades, na codificação). Com base no arquivo de células e em alguns critérios que julgamos pertinentes, reagrupamos alguns grupos de fatores. Como persistisse número elevado de variantes, eliminamos alguns grupos de fatores (doravante GFs.):

\footnotetext{
${ }^{17}$ Ver em Menon (1996) os resultados das rodadas conjuntas e as análises correspondentes. No presente estudo, além das rodadas já efetuadas naquele estudo, procedemos a um refinamento da comparação entre os desempenhos dos grupos de fatores rodados separadamente em função dos limites do programa VARBRUL, conforme se evidenciará na seqüência.

${ }^{18}$ A gente permanece em uso na língua portuguesa do Brasil como um dos pronomes que pode ter referência indeterminada. Ver em Menon $(1994 b, 1995 a, c)$ que essa é a etapa da gramaticalização que possibilita a interpretação de a gente como nós e que provavelmente é a porta de acesso da interpretação pessoal do pronome, visto que, como genérico, a gente pode conter eu/nós.

${ }^{19}$ Knockouts são resultados polarizados: ou o número de ocorrências no grupo de fatores ou variável corresponde a $100 \%$, ou não há ocorrências. Isso significa que ou não está havendo variação naquele grupo de fatores ou, ainda, que não há ocorrência daqueles dados no córpus; portanto, ele deve ser retirado da amostra (ou amalgamado com outros dados, se for pertinente fazê-lo).
} 
1. posição do pronome em relação ao verbo: 996 dados ocorreram antes do verbo e somente 14 depois do verbo. Os outros 550 dados apareceram como não se aplica, critério empregado quando o pronome estava ausente, por não se poder posicioná-lo em relação ao verbo;

2. marcas auxiliares: GF eliminado das rodadas por ter apresentado número muito pequeno de ocorrências, 103/ 1560, com 05 nocautes.

3. concordância com o infinitivo, visto que em 1462 casos esse fator não se aplicava e, nos restantes, dois nocautes já indicavam que provavelmente não haveria pertinência desse fator na aplicação da regra.

Depois das eliminações acima, mais o reagrupamento dos fatores, ainda não foi possível fazer atuar todos os GFs conjuntamente, face ao número total de células. Assim, tivemos de realizar rodadas em conjunto (programa MVARB ${ }^{20}$ ), para testar alguns GFs. e depois fizemos outras, com os mesmos GFs., mas separadamente para eu e para nós, para a comparabilidade. Posteriormente, fizemos rodadas com fatores que não tinham sido incluídos nas anteriores, jogando com os fatores sociais, para ver se eles interfeririam nos resultados. Com isso, poderíamos testar se os condicionamentos mais fortes na aplicação da regra variável preenchimento do sujeito pronominal de 1 . $^{\mathrm{a}}$ pessoa seriam os lingüísticos ou os sociais.

Em termos de freqüencia, a amostra estudada evidenciou um maior emprego do pronome junto ao verbo: $67 \%$ para eu e $61 \%$ para nós.

Os resultados da nossa amostra são coerentes com outros estudos já realizados. Monteiro (1994, p.134-135), por exemplo, obteve em seus dados da amostra compartilhada do NURC ${ }^{21}$ os percentuais de 61 para eu e 64 para nós, pesos relativos de 0,50 e 0,52 , respectivamente (o autor considerou todas as pessoas em conjunto), na aplicação da regra de uso do pronome junto ao verbo. Depois, fazendo rodadas opondo os pronomes de primeira aos de terceira, com neutralização da oposição de número, constatou que os "de primeira pessoa ocorrem mesmo em maior escala $(0,50)$ que os de terceira $(0,32)$."

Botassini (1998), trabalhando com dados do Projeto VARSUL (Variação Lingüística Urbana na Região Sul), referentes às cidades do Paraná: Curitiba, Irati, Londrina e Pato Branco, obteve uma amostra de 24181 ocorrências de pronome de primeira pessoa. Dessas, 21334 são de primeira pessoa do singular e 2847 são de primeira pessoa do plural. Em termos de freqüência ${ }^{22}$, a mostra do VARSUL (constituída de informantes de três níveis de escolaridade (primário, ginásio,

${ }^{20}$ Não faremos referência, aqui, aos resultados dessas rodadas. Consultar Menon (1996).

${ }^{21} 60$ entrevistas (45 DIDs e $15 \mathrm{EFs}$ ), assim distribuídas: 12 por região (Rio de Janeiro, São Paulo, Porto Alegre, Salvador e Recife); 30 de cada sexo e 20 de cada faixa etária.

22 Lembramos que os resultados em termos de freqüencia, ou percentuais, indicam somente a distribuição das variantes no córpus. Em hipótese alguma podem ser considerados como aplicação da regra; esta só é obtida através do programa VARBRUL, e será expressa por pesos relativos. 
colegial $^{23}$ ) apresenta resultados muito semelhantes aos da nossa amostra: $61 \%$ das ocorrências de eu e $57 \%$ das ocorrências de nós têm sujeito preenchido. No tocante à distribuição por escolaridade, a amostra do VARSUL não evidenciou diferenças significativas, que pudessem comprovar que a escolaridade maior implicaria um menor emprego do pronome. Veja-se a Fig. 1, abaixo, construída a partir dos resultados de Botassini:

Distribuição (freqüência) das ocorrências no uso do pronome sujeito de 1. ${ }^{a}$ pessoa na amostra VARSUL/PR, com os pesos para a aplicação da regra, por escolaridade.

\begin{tabular}{|c|c|c|c|c|c|}
\hline Escolaridade EU & $\%$ & $\begin{array}{c}\text { PESO } \\
\text { RELATIVO }\end{array}$ & Escolaridade NOS & $\%$ & $\begin{array}{c}\text { PESO } \\
\text { RELATIVO }\end{array}$ \\
\hline Primário & 62 & 0,51 & Primário & 57 & 0,50 \\
\hline Ginásio & 60 & 0,49 & Ginásio & 59 & 0,51 \\
\hline Colegial & 61 & 0,50 & Colegial & 57 & 0,49 \\
\hline \multicolumn{7}{|c}{ Fig.1 }
\end{tabular}

Podemos considerar, então que, apesar dos mais de vinte anos que separam as coletas do NURC e do VARSUL, além do fato de serem variedades diversamente localizadas no plano geográfico, não há diferenças significativas no que diz respeito ao resultado da distribuição das amostras. Sem levar em conta a questão da aplicabilidade da regra de preenchimento do pronome sujeito, poderíamos deduzir que esse é um fenômeno variável relativamente estável (no sentido da abrangência dialetal) no português do Brasil e poderia se caracterizar como variação inerente. A testagem por região, na amostra VARSUL, não foi significativa, com os pesos relativos não se afastando do ponto neutro mais de dois pontos (BOTASSINI, 1998, p.89). Cada cidade do VARSUL, em cada estado, foi escolhida por ter sofrido ocupação do território por grupos distintos. No caso do Paraná, além da capital, que também é representante da ocupação mais antiga do território, Irati representa a região de colonização eslava; Londrina, a ocupação mineiro-paulista; Pato Branco, a ocupação gaúcho-catarinense. Como os resultados não apontaram maior ou menor aplicação da regra e, estendendo esses resultados às regiões de origem dos grupos povoadores, no caso de Curitiba, Londrina e Pato Branco, corrobora-se a hipótese de ser um caso de variação inerente. No entanto, as amostras (incluindo outras, citadas na introdução), por testarem grupos de fatores diferentes, não podem ser comparadas integralmente, por não poderem ser rodadas juntas ou cotejadas fator a fator.

A Fig. 2 apresenta os resultados obtidos em nossa amostra, após a limpeza dos grupos de fatores que foram eliminados ou amalgamados. Apesar de constar da primeira rodada no VARB2000, de Menon (1996), o GF tipo de verbo não consta

${ }^{23}$ Utilizou-se no Varsul a denominação antiga dos três níveis de ensino, que correspondem, respectivamente, a quatro, oito e onze anos de escolaridade. 
da discriminação abaixo, por ter sido descartado como estatisticamente não relevante ${ }^{24}$ para os dois pronomes já naquela rodada.

Procedemos, então, a rodadas separadas pois o número de GFs, no total, ultrapassava o limite permitido pelo VARBRUL. Assim, no primeiro momento, os GFs considerados foram determinação, tempo verbal, tipo de verbo, tipo de ocorrência, sexo, faixa etária. A seleção dos GFs considerados estatisticamente relevantes para a aplicação da regra - uso do pronome junto ao verbo - pode ser vista na Fig. 3, de resumo das rodadas. Como nessa rodada não foi possível incluir o GF tipo de oração, passou-se a novo procedimento, com rodada a partir dos grupos de fatores lingüisticos tipo de ocorrência, tipo de oração, tipo de conjunção, e com os fatores sociais sexo, faixa etária.

Em rodada adicional, somente com os grupos de fatores tipo de ocorrência, tipo de oração, tipo de conjunção, no stepup da rodada para EU todos os grupos de fatores foram considerados; nenhum GF foi descartado no stepdown. No entanto, ao adicionar o grupo 3, tipo de conjunção, piora o nível de significância (.042), embora o log likelihood diminua em relação aos dois níveis anteriores (-462.134). Na rodada de NÓS, porém, o stepup seleciona somente o GF tipo de oração e o stepdown descarta os outros dois grupos.

Para nos certificarmos do apresentado nessas rodadas parciais e verificarmos se, realmente, tipo de oração seria o GF mais importante na aplicação da regra, resolvemos, então, testar novamente os GFs, fazendo nova rodada, desta feita com os GFs indeterminação, tempo verbal, tipo de ocorrência, tipo de oração, sexo e idade. A fim de rodar o programa com o máximo de GFs permitido, eliminamos tipo de conjunção (que poderia estar se sobrepondo a tipo de oração e enviesando resultados) e tipo de verbo, que já havia sido desconsiderado pelo programa nas rodadas iniciais. Mantivemos, porém, sexo pois esse grupo de fatores ora tinha sido selecionado, ora rejeitado. Pudemos, assim, testar juntos os GFs que, em outras rodadas, se mostraram relevantes. Obteve-se o seguinte ${ }^{25}$ :

a) na rodada para testar a probabilidade de aplicação da regra no uso do pronome eu, no stepup foram selecionados, pela ordem de relevância, os GFs tipo de oração, tempo verbal, idade, indeterminação, tipo de ocorrência (o log likelihood foi de -448.629 e a significance foi de .017). No stepdown, sexo foi rejeitado, confirmando a não-relevância desse GF; além disso, na ordem de relevância, os testes efetuados pelo programa mostraram que sem o GF determinação (sem sexo) melhora a significance (.000) apesar de elevar o log likelihood (-456.904). Comparando os resultados com acréscimos ou retirada dos GFs. determinação, idade, sexo, percebe-se que, apesar de o programa continuar a considerá-los significativos para a análise, eles não são tão incisivos no uso do pronome $\mathrm{eu}$;

\footnotetext{
${ }^{24}$ Resultado diferente daquele encontrado por Silva \& Faccio (1981, p.202), em que os verbos de opinião (achar, pensar, crer ...) condicionavam elevado uso do pronome de primeira pessoa.

${ }^{25}$ Ver Fig. 3, que resume as rodadas de seleção de GFs. 
b) na rodada para nós, no stepup foram selecionados, pela ordem, os GFs determinação, tempo verbal, idade, tipo de oração. Dois GFs não foram considerados relevantes: tipo de ocorrência e sexo. No stepdown, o programa rejeita o GF tipo de ocorrência, não confirma a não-relevância de sexo e descarta o grupo tipo de oração (os colchetes indicam, na tabela, essa situação). Temos, dessa forma, um resultado conflitante com a rodada anterior, pois esse último GF tinha se evidenciado, ali, como o único relevante.

Distribuição dos dados da amostra por número de ocorrências de preenchimento do pronome sujeito, em cada grupo de fatores e a respectiva freqüência.

\begin{tabular}{|c|c|c|c|c|c|c|}
\hline Tempo verbal & $\begin{array}{c}\text { EU } \\
\text { N/total } \\
\%\end{array}$ & $\begin{array}{c}\text { NÓS } \\
\text { N/total } \\
\% \\
\end{array}$ & \multicolumn{2}{|c|}{ Tipo de ocorrência } & $\begin{array}{c}\text { EU } \\
\text { N/total } \\
\% \\
\end{array}$ & $\begin{array}{c}\text { NÓS: N/tota } \\
\%\end{array}$ \\
\hline Presente do Indicativo & $\begin{array}{c}250 / 372 \\
67 \%\end{array}$ & $\begin{array}{c}174 / 239 \\
73 \%\end{array}$ & \multicolumn{2}{|c|}{ Sujeito anterior $\neq$} & $\begin{array}{c}109 / 129 \\
84 \%\end{array}$ & $\begin{array}{c}76 / 116 \\
66 \%\end{array}$ \\
\hline Imperfeito do Indicativo & $\begin{array}{c}69 / 86 \\
80 \% \\
\end{array}$ & $\begin{array}{c}26 / 30 \\
86 \% \\
\end{array}$ & \multicolumn{2}{|c|}{ Sujeito posterior $\neq$} & $\begin{array}{c}136 / 173 \\
79 \%\end{array}$ & $\begin{array}{c}89 / 138 \\
64 \% \\
\end{array}$ \\
\hline Perfeito do Indicativo & $\begin{array}{c}171 / 234 \\
73 \% \\
\end{array}$ & $\begin{array}{c}33 / 64 \\
52 \% \\
\end{array}$ & \multicolumn{2}{|c|}{ Ocorrência isolada } & $\begin{array}{c}72 / 100 \\
72 \%\end{array}$ & $\begin{array}{c}70 / 100 \\
70 \%\end{array}$ \\
\hline Futuro simples Indicativo & $\begin{array}{c}05 / 11 \\
45 \%\end{array}$ & $\begin{array}{c}04 / 09 \\
44 \%\end{array}$ & \multicolumn{2}{|c|}{$1 .^{\text {a }}$ de série $=(e u, e u / \varnothing \varnothing)$} & $\begin{array}{c}56 / 73 \\
77 \%\end{array}$ & $\begin{array}{c}33 / 54 \\
61 \%\end{array}$ \\
\hline Futuro perifrástico Indicat. & $\begin{array}{l}28 / 37 \\
76 \%\end{array}$ & $\begin{array}{c}51 / 72 \\
71 \%\end{array}$ & \multicolumn{2}{|c|}{$2 .^{\text {a de série }=}$} & $\begin{array}{l}57 / 78 \\
73 \%\end{array}$ & $\begin{array}{c}34 / 55 \\
62 \%\end{array}$ \\
\hline Presente do Subjuntivo & $\begin{array}{l}08 / 09 \\
89 \%\end{array}$ & $\begin{array}{c}04 / 08 \\
50 \%\end{array}$ & \multicolumn{2}{|c|}{$3 .{ }^{\mathrm{a}}$, ou mais, de série $=$} & $\begin{array}{l}17 / 21 \\
81 \% \\
\end{array}$ & $\begin{array}{c}04 / 15 \\
27 \% \\
\end{array}$ \\
\hline Imperfeito do Subjuntivo & $\begin{array}{l}04 / 05 \\
80 \%\end{array}$ & $\begin{array}{c}02 / 04 \\
50 \%\end{array}$ & \multicolumn{2}{|c|}{ Presença + ausência pron. } & $\begin{array}{c}40 / 73 \\
55 \%\end{array}$ & $\begin{array}{c}13 / 26 \\
50 \%\end{array}$ \\
\hline Futuro do subjuntivo & $\begin{array}{c}19 / 82 \\
23 \%\end{array}$ & $\begin{array}{c}20 / 48 \\
42 \%\end{array}$ & \multicolumn{2}{|c|}{ Ausência +presença pron. } & $\begin{array}{c}10 / 21 \\
48 \%\end{array}$ & $\begin{array}{c}08 / 18 \\
44 \%\end{array}$ \\
\hline Condicional & $\begin{array}{c}15 / 23 \\
65 \% \\
\end{array}$ & $\begin{array}{c}18 / 23 \\
78 \% \\
\end{array}$ & \multicolumn{2}{|c|}{ Aus.+ aus. + pres. pron } & $\begin{array}{l}12 / 43 \\
28 \% \\
\end{array}$ & $\begin{array}{c}06 / 18 \\
33 \% \\
\end{array}$ \\
\hline Estar (pres.)+ Gerúndio & $\begin{array}{c}34 / 44 \\
77 \% \\
\end{array}$ & $\begin{array}{c}37 / 48 \\
77 \% \\
\end{array}$ & \multicolumn{2}{|c|}{ Intercalação v. dicendi } & $\begin{array}{c}21 / 45 \\
47 \% \\
\end{array}$ & $\begin{array}{c}06 / 21 \\
29 \% \\
\end{array}$ \\
\hline Ir/andar/acabar + Gerúndio & $\begin{array}{c}04 / 06 \\
67 \%\end{array}$ & $\begin{array}{c}02 / 04 \\
50 \%\end{array}$ & \multicolumn{2}{|c|}{ Presença $+\varnothing+$ pres. pron. } & $\begin{array}{l}46 / 75 \\
61 \%\end{array}$ & $\begin{array}{c}03 / 07 \\
43 \%\end{array}$ \\
\hline MPQ amálgama & $\begin{array}{l}22 / 29 \\
76 \%\end{array}$ & $\begin{array}{c}06 / 73 \\
08 \%\end{array}$ & \multicolumn{2}{|c|}{ Pres.+ pres. $+\varnothing+\varnothing$} & $\begin{array}{c}06 / 15 \\
40 \%\end{array}$ & $\begin{array}{c}06 / 10 \\
60 \%\end{array}$ \\
\hline Total & $\begin{array}{c}629 / 938 \\
67 \%\end{array}$ & $\begin{array}{c}377 / 622 \\
61 \%\end{array}$ & \multicolumn{2}{|c|}{$\varnothing+\mathrm{SN}+$ pronome } & $\begin{array}{c}01 / 02 \\
50 \%\end{array}$ & $\begin{array}{c}01 / 02 \\
50 \%\end{array}$ \\
\hline Sexo & & & \multicolumn{2}{|c|}{ Pres.pron. \pm prepos. +infin. } & $\begin{array}{c}22 / 55 \\
40 \%\end{array}$ & $\begin{array}{c}06 / 11 \\
55 \%\end{array}$ \\
\hline Masculino & \multicolumn{2}{|c|}{$\begin{array}{c}482 / 730 \\
66 \%\end{array}$} & $\begin{array}{c}246 / 404 \\
61 \%\end{array}$ & $\begin{array}{c}\text { Amálgama } \\
\ldots\end{array}$ & $\begin{array}{c}46 / 75 \\
61 \%\end{array}$ & $\begin{array}{c}22 / 31 \\
71 \%\end{array}$ \\
\hline Feminino & \multicolumn{2}{|c|}{$\begin{array}{c}147 / 208 \\
71\end{array}$} & $\begin{array}{c}131 / 218 \\
60 \%\end{array}$ & Total & $\begin{array}{c}629 / 938 \\
67 \%\end{array}$ & $\begin{array}{c}377 / 622 \\
61 \%\end{array}$ \\
\hline Total & \multicolumn{2}{|c|}{$\begin{array}{c}629 / 938 \\
67 \%\end{array}$} & $\begin{array}{c}377 / 622 \\
61 \% \\
\end{array}$ & & & \\
\hline
\end{tabular}




\begin{tabular}{|c|c|c|c|c|c|}
\hline Tipo de oração & EU N/ total=\% & $\begin{array}{l}\text { NÓS N/ } \\
\text { total=\% }\end{array}$ & $\begin{array}{c}\text { Tipo de } \\
\text { conjunção }\end{array}$ & $\begin{array}{c}\text { EU } \\
N / \text { total=\% }\end{array}$ & $\begin{array}{c}\text { NÓS } \\
\text { N/ total=\% }\end{array}$ \\
\hline & & & Aditiva & $30 / 84=36 \%$ & $18 / 44=41 \%$ \\
\hline Absoluta & $72 / 101=71 \%$ & $70 / 100=70 \%$ & Adversativa & $32 / 37=86 \%$ & $09 / 16=56 \%$ \\
\hline 1. ${ }^{\mathrm{a}}$ período coordenado & $74 / 91=81 \%$ & $36 / 53=68 \%$ & Explicativa & $13 / 15=87 \%$ & $05 / 06=83 \%$ \\
\hline Coordenada sindética & $80 / 148=54 \%$ & $36 / 72=50 \%$ & Integrante & $17 / 21=81 \%$ & $13 / 15=87 \%$ \\
\hline Coordenada assindética & $46 / 111=41 \%$ & $24 / 73=33 \%$ & Condicional & $23 / 34=68 \%$ & $17 / 20=85 \%$ \\
\hline Principal & $163 / 213=77 \%$ & $100 / 152=66 \%$ & Final & $19 / 53=36 \%$ & $08 / 22=36 \%$ \\
\hline Adjetiva restritiva & $79 / 85=93 \%$ & $52 / 71=73 \%$ & Temporal & $11 / 13=85 \%$ & $07 / 12=58 \%$ \\
\hline Adverbial & $86 / 129=67 \%$ & $37 / 67=57 \%$ & Causal & $20 / 21=95 \%$ & $05 / 09=56 \%$ \\
\hline Substantiva objet. Direta & $22 / 30=73 \%$ & $10 / 13=77 \%$ & Conformativa & $22 / 23=96 \%$ & $07 / 09=78 \%$ \\
\hline \multirow[t]{3}{*}{ Substantiva subjetiva } & $07 / 30=23 \%$ & $11 / 21=52 \%$ & Pronome relativo & $76 / 82=93 \%$ & $49 / 67=73 \%$ \\
\hline & & & Preposição de & $02 / 22=09 \%$ & $01 / 09=11 \%$ \\
\hline & & & Não se aplica & $\begin{array}{c}364 / 533=68 \\
\%\end{array}$ & $\begin{array}{c}238 / 393=61 \\
\%\end{array}$ \\
\hline Total & $629 / 938=67$ & $377 / 622=61 \%$ & Total & $\begin{array}{c}629 / 938=67 \\
\%\end{array}$ & $\begin{array}{c}377 / 622=61 \\
\%\end{array}$ \\
\hline
\end{tabular}

\begin{tabular}{|c|c|c|c|c|c|}
\hline Faixa etária & $\begin{array}{c}\text { EU } \\
\text { N/total=\% }\end{array}$ & $\begin{array}{c}\text { NÓS } \\
\text { N/total=\% }\end{array}$ & Determinação & $\begin{array}{c}\text { EU } \\
\text { N/total=\% }\end{array}$ & $\begin{array}{c}\text { NÓS } \\
\text { N/total=\% }\end{array}$ \\
\hline FE1 : $25-35$ anoS & $215 / 307=70 \%$ & $139 / 237=59 \%$ & Determinado & $522 / 804=65 \%$ & $21 / 46=46 \%$ \\
\hline FE2:36-55 anoS & $208 / 274=76 \%$ & $194 / 287=68 \%$ & Indeterminado & $94 / 118=80 \%$ & $223 / 296=75 \%$ \\
\hline FE3:+ de 56 anos & $206 / 357=58 \%$ & $44 / 98=45 \%$ & Problema & $13 / 16=81 \%$ & $133 / 280=47 \%$ \\
\hline Total & $629 / 938=67 \%$ & $377 / 622=61 \%$ & Total & $629 / 938=67 \%$ & $377 / 622=61 \%$ \\
\hline
\end{tabular}

Para obter os dados para a análise, procedemos a essa checagem da metodologia, pois os resultados parciais poderiam enviesar a aplicação da regra de uso do pronome sujeito. Como pudemos constatar, se tomássemos somente os resultados das rodadas iniciais, teríamos alguns números bastante diferentes daqueles a que chegamos no final e que estarão discriminados nas Figuras 4 e 5. Por ora, apresentamos o resumo das rodadas efetuadas e os GFs que foram selecionados em cada uma delas.

Resumo das rodadas para testagem da relevância dos Grupos de Fatores na aplicação da regra de uso do pronome sujeito junto ao verbo.

\begin{tabular}{|c|c|c|}
\hline EU - GFs Selecionados & Grupos de fatores da rodada & NÓS - GFs selecionados \\
\hline Faixa etária & Determinação & Determinação \\
Tempo verbal $^{2}$ & Tempo verbal & Tempo verbal \\
[Tipo de verbo] $^{26}$ & Tipo de verbo & Faixa etária \\
Tipo de ocorrência & Tipo de ocorrência & Sexo \\
Determinação & Sexo & \\
& Faixa etária & \\
\hline
\end{tabular}

${ }^{26}$ Os GFs entre colchetes, selecionados no stepup, foram descartados no stepdown. Os GFs. entre parênteses, apesar de selecionados no stepup, pioram a análise.

170 


\begin{tabular}{|c|c|c|}
\hline EU : GFs Selecionados & GFs da rodada & NÓS: GFs Selecionados \\
\hline Tipo de oração & Tipo de ocorrência & Tipo de oração \\
Faixa etária & Tipo de oração \\
(Tipo de conjunção) & Tipo de conjunção & \\
& Sexo etária \\
& Faixa Etária & \\
\hline EU : GFs. Selecionados & GFs. da rodada & NÓS: GFs. Selecionados \\
\hline Tipo de oração & Determinação & Determinação \\
Tempo verbal & Tempo verbal & Tempo verbal \\
Faixa etária & Tipo de ocorrência & Faixa etária \\
Determinação & Tipo de oração & [Tipo de oração] \\
Tipo de ocorrência & Sexo & \\
& Faixa etária & \\
\hline
\end{tabular}

Vemos que tipo de oração foi considerado o GF mais relevante no uso do pronome eu, no entanto, para nós, selecionado no stepup em último lugar ${ }^{27}$, foi descartado no stepdown; determinação, que para o pronome nós é o mais relevante, para eu vem em quarto lugar. Tempo verbal e faixa etária foram identicamente selecionados para os dois pronomes, na mesma ordem. Descartado no stepup para nós, tipo de ocorrência foi selecionado em última posição para eu. Assim, vemos que os fatores estruturais acabam sendo mais determinantes que os sociais, mas têm comportamentos diferenciados na aplicação da regra. Vamos analisar, então, com mais detalhe, alguns dos resultados que obtivemos a partir da amostra, conforme constam nas Figuras 4 e 5:

Rodadas separadas de EU e NÓS, para testagem da relevância dos Grupos de Fatores determinação, tempo verbal, tipo de ocorrência ${ }^{28}$, tipo de oração, sexo e faixa etária, na aplicação da regra de uso do pronome sujeito.

\begin{tabular}{|c|c|c|c|c|c|}
\hline & EU & NÓS & & EU & NÓS \\
\hline Tipo de oração & (01) & [(04)] & Tempo verbal & (02) & (02) \\
\hline Absoluta & 0,34 & 0,55 & Presente do Indicativo & 0,43 & 0,53 \\
\hline 1. ${ }^{\mathrm{a}}$ período coordenado & $\overline{0,69}$ & 0,54 & Imperfeito do Indicativo & 0,81 & 0,89 \\
\hline Coordenada sindética & $\underline{0,31}$ & $\underline{0,34}$ & Perfeito do Indicativo & 0,66 & 0,47 \\
\hline Coordenada assindética & $\underline{0,18}$ & 0,25 & Futuro simples Indicativo & $\underline{0,24}$ & $\underline{0,25}$ \\
\hline Principal & $\overline{0,64}$ & 0,55 & Presente do Subjuntivo & 0,78 & 0,26 \\
\hline Adjetiva restritiva & 0,81 & 0,59 & Imperfeito do Subjuntivo & 0,60 & 0,37 \\
\hline Adverbial & 0,56 & $\underline{0,22}$ & Futuro do subjuntivo & $\underline{0,13}$ & $\underline{0,17}$ \\
\hline Substantiva objetiva direta & 0,64 & 0,74 & Condicional & $\overline{0,48}$ & $\overline{0,51}$ \\
\hline Substantiva subjetiva & 0,41 & 0,56 & & & \\
\hline Faixa etária (FE) & (03) & (03) & Determinação & (04) & (01) \\
\hline FE1 : 25-35 anos & 0,53 & 0,54 & Determinado & 0,46 & 0,49 \\
\hline FE2: $36-55$ anos & 0,61 & 0,57 & Indeterminado & 0,74 & 0,63 \\
\hline FE3: + de 56 anos & 0,39 & 0,22 & Problema & 0,70 & 0,36 \\
\hline
\end{tabular}

${ }^{27}$ Se tivéssemos levado em conta os resultados da rodada intermediária, com número de fatores reduzido, haveria desvio, pois tipo de oração seria considerado o único fator relevante para nós.

${ }^{28}$ Ver Fig. 5 para esses resultados, exclusivamente para o pronome EU. 
O primeiro fator selecionado para eu, tipo de oração, tem como maior fator de aplicação da regra o fato de o pronome estar numa oração subordinada adjetiva restritiva ${ }^{29}$, com peso 0,81, o que coincide com Botassini (1998, p.84, córpus com escolaridade de quatro a onze anos), e também, parcialmente, com Lira (1982, córpus coletado nas favelas do Rio, apud MONTEIRO, 1994, p.137). Na seqüência, favorecem a aplicação a primeira oração de período coordenado $(0,69)$, e as orações principal e subordinada substantiva objetiva direta, com $0,64^{30}$. O uso do pronome é desfavorecido nas orações coordenadas assindéticas $(0,18)$, sindéticas $(0,31)$, absolutas $(0,34)$ e, já se aproximando do ponto neutro, nas subordinadas substantivas subjetivas $(0,41)$. As subordinadas adverbiais ultrapassam muito pouco o ponto neutro, com 0,56 . Como vemos, tanto principais (e primeira da coordenação) como subordinadas apresentam índices altos de aplicação da regra. Não foi possível, neste estudo, retomar os dados e rever a estrutura dos períodos compostos, a fim de estabelecer, talvez, outros GFs para refinar a análise. Também é intrigante o resultado das orações absolutas, uma vez que o fator ocorrência isolada (GF tipo de ocorrência, ver abaixo) apresentou probabilidade de 0,66 . Poderia estar havendo aí uma sobreposição de fatores, que também caberia analisar em trabalho posterior.

Embora os pesos do fator determinação sejam semelhantes em determinado e em indeterminado para os dois pronomes (casos problema são aqueles em que não foi possível decidir entre a interpretação como locutor ou como indeterminado, já que não preenchia todos os requisitos exigidos para tal), eles indicam maior força desse fator no uso do pronome nós, pois aí foi o primeiro fator selecionado. Apesar de o peso ser mais elevado para indeterminado, é interessante ressaltar que é impossível saber se o falante vai usar ou não o pronome nós quando o sujeito tiver referente determinado, ou seja, quando é o locutor mais alguém.

Tempo verbal, selecionado em segundo lugar para ambos os pronomes, mostra diferentes resultados: no caso de nós, os tempos do subjuntivo desfavorecem a presença do pronome e, dentre os do indicativo, somente no imperfeito é que a aplicação da regra se aproxima mais do categórico, com 0,89 . Nos demais tempos, há empate na probabilidade de uso no presente, no perfeito do indicativo e no condicional. Em relação a $e u$, poderíamos dizer que se confirma a hipótese de haver maior probabilidade de emprego do pronome nos tempos menos marcados (imperfeitos, presente do subjuntivo), mas o peso relativo do perfeito $(0,66)$ assim como o do condicional $(0,48)$, do presente $(0,43)$ e, sobretudo, do futuro do subjuntivo $(0,13)$ parecem contradizer essa premissa. Cabe notar, ainda, que para ambos os pronomes, o futuro simples do indicativo e o do subjuntivo

${ }^{29}$ Lembramos aqui o fato de os pronomes pessoais jamais ocorrerem em orações adjetivas explicativas quando o pronome relativo, sujeito da subordinada, retoma anaforicamente o pronome da principal.

${ }^{30}$ Dois tipos de oração atuariam também para nós (objetivas diretas, com ,74 e adjetivas restritivas, com ,59) mas esse GF foi selecionado no stepup apenas em último lugar e, depois, descartado no stepdown; logo, a importância do fator não é a mesma.

172 
desfavorecem a aplicação da regra (haveria fatores de outra ordem, como prosódicos ou estilísticos atuando aí? Ou, ainda, a própria variação que atinge esses dois tempos, o primeiro sofrendo a concorrência da construção [ir+INF] e o segundo sendo confundido com o infinitivo, já que é somente nos verbos fortes que as formas são diferentes?).

No tocante à faixa etária, vemos que em ambos os pronomes há maior aplicação da regra entre os mais jovens: mesmo que na FE2 o peso seja um pouquinho maior que na $\mathrm{FE} 1$, os pesos na FE3 são bem menores, apontando mudança em curso, no tempo aparente.

Além desses grupos de fatores, selecionados para ambos os pronomes, embora em ordem diferenciada, foi considerado relevante o grupo tipo de ocorrência, para o pronome eu.

GF selecionado em (05) para EU: tipo de ocorrência.

\begin{tabular}{|c|c|c|c|}
\hline & Peso rel. & & Peso rel. \\
\hline Sujeito anterior $\neq$ & 0,70 & & \\
\hline Sujeito posterior $\neq$ & 0,48 & Aus.+ aus. + pres. pron & 0,15 \\
\hline Ocorrência isolada & 0,66 & Intercalação v. dicendi & 0,53 \\
\hline 1. ${ }^{\mathrm{a}}$ de série $=(\mathrm{eu}, \mathrm{eu} / \varnothing \varnothing)$ & 0,46 & Presença+ $\varnothing+$ pres. pron. & 0,46 \\
\hline 2. ${ }^{\text {a }}$ de série $=$ & 0,65 & Pres.+ pres. $+\varnothing+\varnothing$ & 0,22 \\
\hline $3 .{ }^{\mathrm{a}}$, ou mais, de série $=$ & 0,75 & $\varnothing+\mathrm{SN}+$ pronome & 0,45 \\
\hline Presença + ausência pron. & 0,30 & Pres.pron. \pm prepos.+infin. & 0,39 \\
\hline Ausência +presença pron. & 0,21 & Amálgama ... & 0,45 \\
\hline
\end{tabular}

Podemos observar na tabela acima que, apesar de o grupo ter sido selecionado como relevante somente em quinto lugar, o resultado na testagem do paralelismo (marcas levam a marcas; zeros levam a zeros) se mostrou muito interessante: à medida que a ocorrência se distancia da primeira, não só se confirma o princípio, mas aumenta a probabilidade de o sujeito ser preenchido. Temos assim:

1. ${ }^{a}$ ocorrência de série igual: $0 \underline{46}>2 .^{a}$ ocorr.: $0 \underline{65}>3 .^{a}$ ocorr. ou mais: 0,75

o que pode sugerir exatamente o esvaziamento do pronome ou da morfologia verbal (quanto mais longe do primeiro, mais necessidade de marcar o sujeito).

Se o sujeito anterior é diferente, a aplicação da regra não deixa dúvida: 0,70; no entanto, se o sujeito posterior for diferente, o peso se aproxima do ponto neutro da aplicação da regra: 0,48. Em ocorrência isolada, há um certo favorecimento na aplicação da regra com 0,66.

No entanto, o resultado mais surpreendente diz respeito justamente à forma verbal mais marcada. Se para eu os resultados mostram pesos diferentes condicionados por fatores como tempo verbal, em que formas não-marcadas favorecem o uso do pronome e as marcadas desfavorecem esse uso, para nós, sempre marcado, os índices de preenchimento da casa do sujeito no caso do 
imperfeito ou do presente do indicativo e do condicional parecem ser incongruentes.

\section{CONCLUSÃO}

Comparando os resultados dos estudos, vemos que a morfologia verbal rica (como é o caso de nós, sempre marcado) não constitui garantia nem justificativa para a manutenção do parâmetro do sujeito nulo, conclusão a que também havia chegado Monteiro (1994, p.139), ao dizer se os pronomes de primeira pessoa alcançam elevadas taxas de presença no córpus de língua falada, a flexão verbal deixa de ter a função inibidora do sujeito pronominal nos termos em que sempre se imaginou.

No entanto, não podemos também ir para o extremo oposto e afirmar que o português já perdeu esse parâmetro. Como quer que seja, há indícios de uma utilização crescente do pronome, se levarmos em consideração a análise em tempo aparente: se comparadas aos mais jovens, as pessoas das faixas etárias mais velhas usam menos o pronome.

Quanto à questão semântica, tanto da marca morfológica quanto dos pronomes, parece estar havendo, em ambos, o processo de bleaching ou desbotamento do significado (uma das condições do processo de gramaticalização). Para os pronomes, estaria acontecendo o mesmo processo que, no francês, levou os pronomes ao extremo da gramaticalização, a cliticização: de pronomes tônicos, com autonomia, os pronomes sujeito do francês teriam perdido o acento e o caráter de palavra lexical quando se tornaram de uso obrigatório; depois, esvaziando-se completamente o significado, se transformaram em clíticos, dependentes do verbo e, por último, na aquisição da língua, não são mais percebidos como unidades separadas, tornando-se prefixos verbais. Nessa situação, as formas tônicas dos pronomes passam a ocupar a função de sujeito, como em:

(1) lui-i-va courir derrière les femmes.

(2) moi-je-vais dormir.

(3) nous-on-s'en va en Turquie cet été.

Estaria havendo uma deriva românica na utilização dos pronomes sujeito? Algumas línguas estariam em etapas mais avançadas do processo, como o francês e outras línguas ou dialetos românicos (BENINCÀ, 1993)? Outras seriam mais resistentes (pelo menos aparentemente), como o espanhol e o italiano?

O português estaria com o processo em curso? Podemos observar que além dos resultados aqui apresentados, há construções com o chamado pronome cópia que, em princípio, está afetando somente a terceira pessoa, como nas relativas, estudadas por Tarallo (1985) ou em enunciados com tópico(?) seguido imediatamente de pronome, sem pausa e sem alteração na entonação, que se ouve freqüentemente na televisão, em entrevistas: 
(4) O processo-ele fica anos parado na justiça.

(5) A menina-ela precisa debutar, é um momento inesquecível na vida dela.

\section{BIBLIOGRAFIA}

ALBÁN, Maria del Rosario et alii. Nós e a gente: uma sondagem na norma culta brasileira. Estudos lingüísticos e literários, Salvador, 11, p. 103-116,1991.

BENINCÀ, Paola. Sintassi. In: BENINCÀ et alii. Introduzione allitaliano contemporaneo. Le strutture. [a cura di Alberto A. Sobrero]. Roma, Bari, Editori Laterza, p. 247-290,1993.

BRAGA, Maria L. \& OMENA, Nelize P. A gente está se gramaticalizando? In: MACEDO, Alzira; RONCARATI, Cláudia; MOLLICA, Cecília (orgs.). Variação e discurso. Rio de Janeiro, Tempo Brasileiro, p. 75-83,1996.

BOTASSINI, Jacqueline O. M. A elipse do sujeito pronominal na linguagem falada no Paraná: uma análise variacionista. Curitiba, UFPR, 1998. Dissertação de Mestrado

CUESTA, Pilar V. \& LUZ, M. Albertina M. da. Gramática da língua portuguesa. São Paulo, Martins Fontes, 1980.

DUARTE, M. Eugênia L. Do pronome nulo ao pronome pleno: a trajetória do sujeito no português do Brasil. In: ROBERTS, I. ; KATO, M. A. (orgs.) Português brasileiro: uma viagem diacrônica. Campinas, Ed. da UNICAMP, p. 107-128, 1993.

. A perda do princípio "evite pronome" no português brasileiro. Campinas, Universidade Estadual de Campinas,1995. Tese de Doutoramento.

FERREIRA, Carlota et alii. A pessoa e a não-pessoa em discursos de informantes do Projeto NURC/Salvador. Estudos lingüisticos e literários, Salvador, 11, p.39-52,1991.

GALVES, Charlote C. O enfraquecimento da concordância no português brasileiro. In: ROBERTS, I. ; KATO, M. A. (orgs.) Português brasileiro: uma viagem diacrônica. Campinas, Ed. da UNICAMP, p. 387-408, 1993.

KATO, Mary A. A elisão do pronome sujeito em português e a hipótese do discurso direto de Kuno. Anais do I Encontro Nacional de Lingüistica Conferências. Rio de Janeiro, PUCRJ, p. 85-135, 1976.

LABOV, William. Sociolinguistic patterns. Philadelphia, University of Pennsylvania Press, 1972.

LIRA, Solange de Azambuja. O sujeito pronominal no português falado e escrito. Ilha do Desterro, Florianópolis, 20, p.31-43,1988.

LOREGIAN, Loremi. Concordância verbal com o pronome tu na fala do sul do Brasil.Florianópolis, UFSC,1996. Dissertação de Mestrado. 
MADVIG, J.N. Grammatica latina, para uso nas escolas. [Trasladada do allemão para portuguez por Augusto Epiphanio da Silva Dias]. Porto, Typographia de Manoel José Pereira, 1872.

MAGNE, Augusto. Grammatica latina. 2 ed. [exemplar encadernado, sem indicação de local e editora],1929.

MENON, Odete P. S. Português: língua de sujeito nulo? I Congresso Internacional da ABRALIN. Salvador, UFBA. Publicado em (1997). Anais do I Congresso ... Volume II (disquete),1994a.

- Analyse sociolinguistique de l'indétermination du sujet dans le portugais parlé au Brésil, à partir des données du NURC/SP. Université Paris VII, 1994b. Tese de Doutorado.

. A gente, eu, nós: sintomas de uma mudança em curso no português do Brasil? II Encontro Nacional sobre Língua Falada e Escrita. Maceió, UFAL. Publicado em (1997). Anais do II ELFE, p. 397-403, 1995a.

. O sistema pronominal do português do Brasil. Revista Letras, Curitiba, 44, p.91-106, 1995 b.

A gente: um processo de gramaticalização. XLIII Seminário do GEL. Ribeirão Preto, UNAERP. Publicado em (1996). Estudos lingüísticos, XXV, p.622-628,1995c.

Usos do pronome sujeito de $1 .{ }^{a}$ pessoa: uma análise sociolingüística. Tese apresentada e aprovada no Concurso para Professor Titular, no Departamento de Lingüística, Letras Clássicas e Vernáculas. Curitiba, UFPR,1996.

. A variação no sistema pronominal do português brasileiro: conseqüências sobre o paradigma verbal. Colóquio Internacional $A$ investigação do português em África, Ásia, América e Europa: balanço e perspectivas. Berlim, Instituto Ibero-Americano, 1998.

MONTEIRO, José L. Pronomes pessoais. Subsídios para uma gramática do português do Brasil. Fortaleza, EUFC,1994.

NARO, Anthony J. \& LEMLE, Myriam. Syntatic diffusion. Ciência e cultura, SBPC, São Paulo, v. 29, n.3, p.259-268, mar. 1977.

NICOLAU, Eunice. Sobre o sujeito nulo no português culto falado no Brasil: resultados parciais da análise quantitativa. I Congresso Internacional da ABRALIN. Salvador, UFBA,1994.

OLIVEIRA, Marco A. Algumas notas sobre o conceito de variável lingüística e sua dimensão nas descrições gramaticais. Boletim da Abralin, 8, p. 87-95,1986.

PAREDES DA SILVA, Vera L. P. da. Cartas cariocas: a variação do sujeito na escrita informal. Rio de Janeiro, UFRJ,1988. Tese de Doutorado.

PONTES, Eunice S. L. Sujeito: da sintaxe ao discurso. São Paulo, Ática, Brasília, INL — Fundação Nacional Pró-Memória,1986.

O tópico no português do Brasil. Campinas, Pontes, 1987.

ROBERTS, Ian. O português brasileiro no contexto das línguas românicas. In: ROBERTS, I. ; KATO, M. A. (orgs.) Português brasileiro: uma viagem diacrônica. Campinas, Ed. da UNICAMP, p. 409-421,1993. 
SAID ALI, M. Gramática histórica da língua portuguesa. 7.ed. Rio de Janeiro, Acadêmica,Melhoramentos, 1971.

SILVA, Wilma \& FACCIO, Luíza. O pronome pessoal na norma urbana culta de São Paulo. Estudos lingüísticos (Anais Sem. do GEL), Araraquara, 4, p.198221,1981 .

SOARES, Maria Maura C. Cezário. A variação do sujeito na primeira pessoa do singular. Rio de Janeiro, Universidade Federal do Rio de Janeiro,1994. Dissertação de Mestrado.

TARALLO, Fernando. The filling of the gap: Pro-drop rules in Brazilian Portuguese. In: KING, Larry D. \& MALEY, Catherine A. (eds.). Selected papers from the XIIIth Linguistic Symposium on Romance Languages. Amsterdam,Philadelphia, J. Benjamins, p. 355-374,1985. 